\title{
Right ventricular remodeling after conduit replacement in patients with corrected tetralogy of Fallot - evaluation by cardiac magnetic resonance
}

\author{
Henrik Guné ${ }^{1}$, Johan Sjögren ${ }^{1}$, Marcus Carlsson², Ronny Gustafsson ${ }^{1}$, Pia Sjöberg ${ }^{2}$ and Shahab Nozohoor ${ }^{1 *}$ (D)
}

\begin{abstract}
Purpose: To evaluate the potential for right ventricular reverse remodelling after pulmonary valve replacement using cardiac magnetic resonance imaging, in adults with corrected tetralogy of Fallot and severe pulmonary insufficiency.

Material and methods: Ten patients with previous correction of tetralogy of Fallot with severe pulmonary insufficiency accepted for pulmonary valve replacement were evaluated prospectively with cardiac magnetic resonance imaging preoperatively and re-evaluated $10 \pm 5$ months postoperatively. Follow up for survival was 100\% complete with mean of $37 \pm 12$ months.

Results: The preoperative mean indexed right ventricular end-diastolic volume was reduced from $161 \pm 33 \mathrm{ml} / \mathrm{m}^{2}$ to $120 \pm 23 \mathrm{ml} / \mathrm{m}^{2}$ postoperatively, $p<0.001$. The preoperative mean indexed right ventricular stroke volume was reduced from $72 \pm 20 \mathrm{ml} / \mathrm{m}^{2}$ to $50 \pm 6 \mathrm{ml} / \mathrm{m}^{2}$ postoperatively, $p=0.002$. After pulmonary valve replacement, the right ventricular ejection fraction did not change significantly (46\% versus $42 \%, p=0.337$ ). Pulmonary insufficiency fraction decreased from $49 \% \pm 11$ to $1 \% \pm 1$ postoperatively, $p<0.001$.

Conclusions: Pulmonary valve replacement leads to a favourable early reverse remodelling with a reduction in RV volumes and improved function in all patients regardless of their preoperative indexed right ventricular volume.
\end{abstract}

Keywords: Adult congenital heart disease, Pulmonary valve replacement, Outcome, Right ventricular function

\section{Introduction}

Tetralogy of Fallot (TOF) is one of the most common forms of cyanotic congenital heart disease. Patients with TOF undergo cardiac surgery in the early years of childhood. Surgical correction is performed with excellent results and early mortality is low [1]. However, cardiac interventions in children are seldom of a curative nature and many patients require corrective procedures, palliative procedures and reoperations reaching adolescence and adulthood [2]. Pulmonary insufficiency (PI) secondary to pulmonary conduit failure is the most common residual finding during mid- to long-term follow-up and the most

\footnotetext{
* Correspondence: shahab.nozohoor@med.lu.se

${ }^{1}$ Department of Cardiothoracic Surgery, Clinical sciences, Lund University,

Skane University Hospital, SE-221 85 Lund, Sweden

Full list of author information is available at the end of the article
}

common indication for re-operation [3, 4]. Previously considered a benign lesion, studies show that PI leads to a dilatation of the right ventricle [5] and an impaired right ventricular function $[5,6]$. Eventually, PI leads to RV dilatation with poor exercise tolerance [7] and long-term morbidity with potential lethal complications such as arrhythmias and sudden death [8]. The golden standard treatment for PI in patients with corrected TOF is pulmonary valve replacement (PVR) with a bioprosthesis or a conduit [9]. However, the timing of PVR in conduit failure and secondary PI remains a subject of debate and the current ESC Guidelines for the Management of Grown-up Congenital Heart Disease and the 2008 ACC/AHA guidelines show that normalization of right ventricular size after re-intervention becomes unlikely as the end-diastolic volume index exceeds $160 \mathrm{~mL} / \mathrm{m}^{2}[10,11]$. The aim of this

(C) The Author(s). 2019 Open Access This article is distributed under the terms of the Creative Commons Attribution 4.0 International License (http://creativecommons.org/licenses/by/4.0/), which permits unrestricted use, distribution, and 
study was to evaluate the potential for RV reverse remodelling after PVR using cardiac magnetic resonance imaging (cMRI), in adults with corrected TOF and severe late PI.

\section{Materials and methods Study design}

The present study was a prospective, non-randomized observational study in which patients with previous correction of TOF with severe PI accepted for PVR were included. Patients were evaluated with cMRI preoperatively and re-evaluated 6 to 12 months postoperatively, according to a study protocol. Permission to proceed with this study was granted by the institutional Ethics Review Board, Lund, Sweden and individual consent was obtained from all patients enrolled.

\section{Indication for PVR}

The current indications for PVR for severe PI in patients with corrected TOF according to the most recent guidelines $[10,11]$ are based on the presence of symptoms (Class I). In asymptomatic patients, the indications are restricted to the following situations: decrease in exercise tolerance according to objective tests; deterioration in RV function and RV dilatation; presence of sustained atrial and/or ventricular arrhythmias; tricuspid regurgitation (at least moderate); and RV outflow tract obstruction (Class IIa). In the current study, PVR was indicated due to the presence of severe PI and RV dilatation in all cases but two. In the first case progressive symptoms of fatigue and dyspnoea (NYHA II) in addition to PI and RV dilatation contributed to the interventional decision. In the second case, PVR was indicated on progressive symptoms alone.

\section{Surgical technique}

The RVOT Elan ${ }^{\text {Tx }}$ (Vascutek, Renfrewshire, UK) conduit $(n=5)$ [12] or the St Jude Epic mitral (St Jude ${ }^{\mathrm{Tx}}$ Medical, Inc., St Paul, Minn, US.) bioprosthetic valve $(n=5)$, was implanted by one expert surgeon in adults with congenital heart disease. All implantations were performed on cardiopulmonary bypass support and moderate hypothermia. The majority of the procedures $(n=8)$ were performed without cardioplegic arrest. When necessary, myocardial protection was achieved with cold blood anterograde cardioplegia. Valve sizing was based on preoperative magnetic resonance imaging as well as intraoperative assessment of the RV outflow tract. Adequate function of the prosthesis was assessed by intraoperative transoesophageal echocardiography immediately after weaning from cardiopulmonary bypass. Postoperative anticoagulation consisted of acetylsalicylic acid $(75 \mathrm{mg})$ three months postoperatively and low-molecular-weight heparin administered during the immobilization phase in the early postoperative period.

\section{Cardiac magnetic resonance imaging}

Cardiac magnetic resonance imaging was the primary investigation technique for evaluation of RV hemodynamics [13-15]. Patients were examined in the supine position using retrospective ECG triggering with a $1.5 \mathrm{~T}$ Philips Achieva scanner (Philips Healthcare, Best, The Netherlands) or $1.5 \mathrm{~T}$ MAGNETOM Aera (Siemens Healthcare $\mathrm{GmbH}$, Erlangen, Germany). Steady-state free precession cine images covering the entire heart was acquired. Typical imaging parameters for Philips scanner were TR/TE: $2.8 / 1.4$, flip angle: $60^{\circ}$, slice thickness: $8 \mathrm{~mm}$, no gap, reconstructed spatial resolution: $1.4 \times 1.4 \times 8$ $\mathrm{mm} 3$, acquired temporal resolution $47 \mathrm{~ms}$ and for the Siemens scanner TR/TE: $2.7 / 1.2$, flip angle: $70^{\circ}$, slice thickness: $8 \mathrm{~mm}$, no gap, reconstructed spatial resolution: $1.2 \times$ $1.2 \times 8 \mathrm{~mm} 3$, acquired temporal resolution $43 \mathrm{~ms}$. $2 \mathrm{D}$ through-plane flow measurements were performed in the ascending aorta and pulmonary artery to measure the effective stroke volume (SV) and pulmonary regurgitation. The freely available software Segment (http://segment. heiberg.se) was used for all image analysis [16].

\section{Follow up}

Follow-up was performed in February 2017 and was $100 \%$ complete for survival (mean $37 \pm 12$ months, interquartile range 26-48). Follow-up with cMRI was performed after a mean of $10 \pm 5$ months postoperatively and was $100 \%$ complete.

\section{Definitions}

Mean indexed RV end-diastolic volume (RVEDVI) was considered normal if $\leq 99 \mathrm{ml} / \mathrm{m}^{2}$, RV end-systolic volume (RVESVI) was considered normal if $\leq 41 \mathrm{ml} / \mathrm{m}^{2}$, and mean indexed RV stroke volume (RVSVI) was considered normal if $\leq 65$ [17]. Postoperative bleeding was defined as bleeding leading to exploration; postoperative heart failure was defined as the need for postoperative inotropic support (norepinephrine and/or dobutamine infusion) for more than $24 \mathrm{~h}$; acute myocardial infarction was diagnosed by electrocardiography (ECG) (new permanent Q-wave), echocardiogram (regional wall movement abnormalities) and cardiac enzymes (aspartate aminotransferase $(\mathrm{AST})>2 \mu \mathrm{kat} / \mathrm{L}$ or creatine kinase myocardial specific isoform (CK-MB) $>50 \mu \mathrm{g} / \mathrm{L})$; postoperative atrial fibrillation (AF) was defined as one or recurrent episodes of supraventricular tachyarrhythmia after cardiac surgery, monitored by continuous telemetry ECG or with an ECG recording using atrial epicardial leads. Early mortality was defined as all-cause mortality within 30 days of surgery. 


\section{Statistics}

Descriptive data are presented as number (\%) or mean \pm SD. All data were indexed for body surface area. The two-tailed paired Student's t-test was used to compare the intra-individual pre-operative and postoperative data. In addition, Wilcoxon Rank test was used, compensating for lack of normal distribution. A $p$-value less than 0.05 was considered statistically significant. Statistical analyses were performed with the statistical software package SPSS (Version 21.0, IBM, Armonk, NY).

\section{Results}

\section{Patient population}

Patient characteristics are presented in Table 1. Mean age at the initial corrective procedure for TOF was $6 \pm 9$ years (median 1.8 years; range $0.3-29$ years). Four patients underwent a palliative procedure (Blalock-Taussig shunt) before correction. Four patients had additional interventions post initial correction for TOF - three had pulmonary artery homograft implantation and one had a left pulmonary artery stent. One patient had undergone a percutaneous attempt of pulmonary valve replacement. However, the procedure was unsuccessful and conventional PVR was required.

Table 1 Baseline demographics $(n=10)$

\begin{tabular}{|c|c|}
\hline Age (years) & $32 \pm 12$ \\
\hline Sex (female) & $4(40)$ \\
\hline Body surface area $\left(m^{2}\right)$ & $1.9 \pm 0.2$ \\
\hline Body mass index $\left(\mathrm{kg} / \mathrm{m}^{2}\right)$ & $26 \pm 5.5$ \\
\hline Any cardiac medication & $1(10)$ \\
\hline Diabetes mellitus & 0 \\
\hline Hypertension & 0 \\
\hline Current smoker & 0 \\
\hline No of previous interventions & $1.5 \pm 0.5$ \\
\hline History of arrythmia & 0 \\
\hline \multicolumn{2}{|l|}{ NYHA class } \\
\hline 1 & $8(80)$ \\
\hline$\|$ & $2(20)$ \\
\hline \multicolumn{2}{|l|}{ Laboratory values } \\
\hline S-creatinine $(\mu \mathrm{mol} / \mathrm{L})$ & $64 \pm 16$ \\
\hline B-Haemoglobin (g/L) & $144 \pm 11$ \\
\hline Surgical correction for TOF & $6 \pm 9$ \\
\hline \multicolumn{2}{|c|}{ Age at primary correction (years) } \\
\hline Previous palliative shunt & $4(40)$ \\
\hline BT-shunt & \\
\hline
\end{tabular}

Values are expressed as number (\%) or mean \pm SD (median, range); NYHA, New York Heart Association; eGFR, estimated Glomerular filtration rate; TOF, Tetralogy of Fallot; BT-shunt, Blalock-Taussig shunt

\section{Intra- and postoperative data}

There was no intraoperative or early mortality. The mean time interval since the last intervention was $20 \pm$ 14 years. The mean pulmonary prosthetic valve size was $25 \pm 1.5 \mathrm{~mm}$. Intraoperative data and postoperative outcome are demonstrated in Table 2. Postoperative complications occurred in 3 (30\%) patients, including sternal infection $(n=1)$, supraventricular tachycardia $(n=1)$, and low cardiac output syndrome $(n=1)$. One patient presented with dyspnoea and flank pain three weeks postoperatively and was diagnosed with pulmonary embolism. The patient was subsequently treated with Warfarin and the medical work up revealed a heterozygote carrier for the prothrombin gene mutation. The mean length of postoperative hospitalization was $10 \pm 4$ days. All patients were alive at the time of follow-up.

\section{Hemodynamic data}

Pre- and postoperative cMRI data are in presented in Table 3. Preoperatively, all patients had at least a moderate PI. The PI fraction decreased from $49 \% \pm 11$ to $1 \% \pm$ 1 postoperatively, $p<0.001$. The preoperative RVEDVI

Table 2 Intra- and postoperative characteristics

\begin{tabular}{|c|c|}
\hline \multicolumn{2}{|l|}{ Type of conduit } \\
\hline Epic bioprosthetic mitral valve conduit & $5(50)$ \\
\hline RVOT Elan bioprosthetic heart valve conduit & $5(50)$ \\
\hline \multicolumn{2}{|l|}{ Pulmonary valve replacement } \\
\hline Perfusion time (min) & $85 \pm 20$ \\
\hline Aortic cross-clamping (min) & $7 \pm 15$ \\
\hline Lowest temperature $\left({ }^{\circ} \mathrm{C}\right)$ & $35 \pm 1$ \\
\hline \multicolumn{2}{|l|}{ Previous interventions } \\
\hline PA-homograft & $3(30)$ \\
\hline LPA-stent & $1(10)$ \\
\hline \multicolumn{2}{|l|}{ Palliative procedures } \\
\hline BT-shunt & $4(40)$ \\
\hline Time since last intervention (years) & $20 \pm 14$ \\
\hline Time since total correction & $27 \pm 11$ \\
\hline Complications & $1(10)$ \\
\hline \multicolumn{2}{|l|}{ Arrhythmia } \\
\hline New onset SVT & $1(10)$ \\
\hline Infection & $1(10)$ \\
\hline Pre-sternal & 0 \\
\hline Heart failure & $1(10)$ \\
\hline \multicolumn{2}{|l|}{ Myocardial infarction } \\
\hline Other complications & $10 \pm 4$ \\
\hline \multicolumn{2}{|l|}{ Postoperative hospitalization (days) } \\
\hline Duration ICU stay (days) & $1 \pm 0$ \\
\hline
\end{tabular}

Values are expressed as number (\%) or mean \pm SD (median, range); PA-homograft, pulmonary artery homograft valve; LPA-stent, placement of stent in the left pulmonary artery; SVT supra-ventricular tachycardia, ICU Intensive care unit 
Table 3 Pre- and postoperative hemodynamic data (cMRI)

\begin{tabular}{|c|c|c|c|c|}
\hline Variables $(n=10)$ & Before PVR & After PVR & Students t-test & Wilcoxon Signed Rank Test \\
\hline RVEDV (ml) & $309 \pm 85$ & $231 \pm 45$ & 0.001 & 0.005 \\
\hline RVEDVI $\left(\mathrm{ml} / \mathrm{m}^{2}\right)$ & $161 \pm 33$ & $120 \pm 23$ & $<0.001$ & 0.005 \\
\hline RVESV (ml) & $171 \pm 58$ & $136 \pm 40$ & 0.043 & 0.047 \\
\hline RVESVI $\left(\mathrm{ml} / \mathrm{m}^{2}\right)$ & $89 \pm 25$ & $71 \pm 21$ & 0.036 & 0.047 \\
\hline RVSV (ml) & $138 \pm 45$ & $95 \pm 13$ & 0.006 & 0.005 \\
\hline $\operatorname{RVSVI}\left(\mathrm{ml} / \mathrm{m}^{2}\right)$ & $72 \pm 20$ & $50 \pm 6$ & 0.002 & 0.005 \\
\hline RVEF (\%) & $46 \pm 11$ & $42 \pm 9$ & 0.337 & 0.373 \\
\hline LVEDV (ml) & $149 \pm 22$ & $171 \pm 28$ & 0.002 & 0.007 \\
\hline LVEDVI $\left(\mathrm{ml} / \mathrm{m}^{2}\right)$ & $79 \pm 10$ & $90 \pm 15$ & 0.012 & 0.015 \\
\hline LVESV (ml) & $68 \pm 17$ & $76 \pm 20$ & 0.213 & 0.236 \\
\hline LVESVI $\left(\mathrm{ml} / \mathrm{m}^{2}\right)$ & $36 \pm 8$ & $40 \pm 11$ & 0.271 & 0.284 \\
\hline LVSV (ml) & $81 \pm 12$ & $95 \pm 12$ & $<0.001$ & 0.005 \\
\hline LVSVI $\left(\mathrm{ml} / \mathrm{m}^{2}\right)$ & $43 \pm 7$ & $50 \pm 6$ & 0.001 & 0.005 \\
\hline LVEF (\%) & $55 \pm 7$ & $56 \pm 6$ & 0.656 & 0.593 \\
\hline PI (\%) & $49 \pm 11$ & $1 \pm 1$ & $<0.001$ & NA \\
\hline MPA netflow (mL/min) & $5100 \pm 1500$ & $6100 \pm 800$ & 0.120 & 0.139 \\
\hline
\end{tabular}

Values are expressed as number (\%) or mean \pm SD (median, range); EF, ejection fraction; RVEDV, right ventricular end-diastolic volume; RVESV, right ventricular end-systolic volume; RVSV, right ventricular stroke volume; LVEDV, left ventricular end-diastolic volume; LVESV, left ventricular end-systolic volume; LVSV, left ventricular stroke volume; PI, pulmonary insufficiency; MPA, main pulmonary artery

was reduced from $161 \pm 33 \mathrm{ml} / \mathrm{m}^{2}$ (range, 91 to $212 \mathrm{ml} /$ $\mathrm{m}^{2}$ ) to $120 \pm 23 \mathrm{ml} / \mathrm{m}^{2}$ (range, 80 to $157 \mathrm{ml} / \mathrm{m}^{2}$ ) postoperatively, $p<0.001$ (Fig. 1). The preoperative RVESVI was reduced from $89 \pm 25 \mathrm{ml} / \mathrm{m}^{2}$ (range, 28 to $125 \mathrm{ml} /$ $\mathrm{m}^{2}$ ) to $71 \pm 21 \mathrm{ml} / \mathrm{m}^{2}$ (range, 29 to $106 \mathrm{ml} / \mathrm{m}^{2}$ ) postoperatively, $p=0.036$. The pre- and postoperative RVEDVI for each patient is shown in Fig. 1. After PVR, the RVEF did not change significantly ( $46 \%$ versus $42 \%, p=0.337$ ). The preoperative RVSVI was reduced from $72 \pm 20 \mathrm{ml} /$ $\mathrm{m}^{2}$ (range 43 to $107 \mathrm{ml} / \mathrm{m}^{2}$ ) to $50 \pm 6 \mathrm{ml} / \mathrm{m}^{2}$ (range 37 to $57 \mathrm{ml} / \mathrm{m}^{2}$ ) postoperatively, $p=0.002$. The preoperative mean net flow in the main pulmonary artery (MPA) was
$5100 \pm 1500 \mathrm{ml} / \mathrm{min}$ (range, 3300 to $7700 \mathrm{ml} / \mathrm{min}$ ) with an increase to mean $6100 \pm 800 \mathrm{ml} / \mathrm{min}$ (range, 5400 to $8000 \mathrm{ml} / \mathrm{min}$ ) postoperatively, $p=0.120$.

The preoperative mean indexed left ventricular stroke volume (LVSVI) increased from $43 \pm 7 \mathrm{ml} / \mathrm{m}^{2}$ (range, 33 to $56 \mathrm{ml} / \mathrm{m}^{2}$ ) to $50 \pm 6 \mathrm{ml} / \mathrm{m}^{2}$ (range, 40 to $58 \mathrm{ml} / \mathrm{m}^{2}$ ) postoperatively, $p=0.001$. The preoperative mean indexed left ventricular end-systolic volume (LVESVI) increased from $36 \pm 8 \mathrm{ml} / \mathrm{m}^{2}$ (range, 26 to $48 \mathrm{ml} / \mathrm{m}^{2}$ ) to $40 \pm 11 \mathrm{ml} / \mathrm{m}^{2}$ (range, 21 to $58 \mathrm{ml} / \mathrm{m}^{2}$ ) postoperatively, $p=0.271$. The preoperative mean indexed left ventricular end-diastolic volume (LVEDVI) increased from $79 \pm 10 \mathrm{ml} / \mathrm{m}^{2}$ (range, 77 to

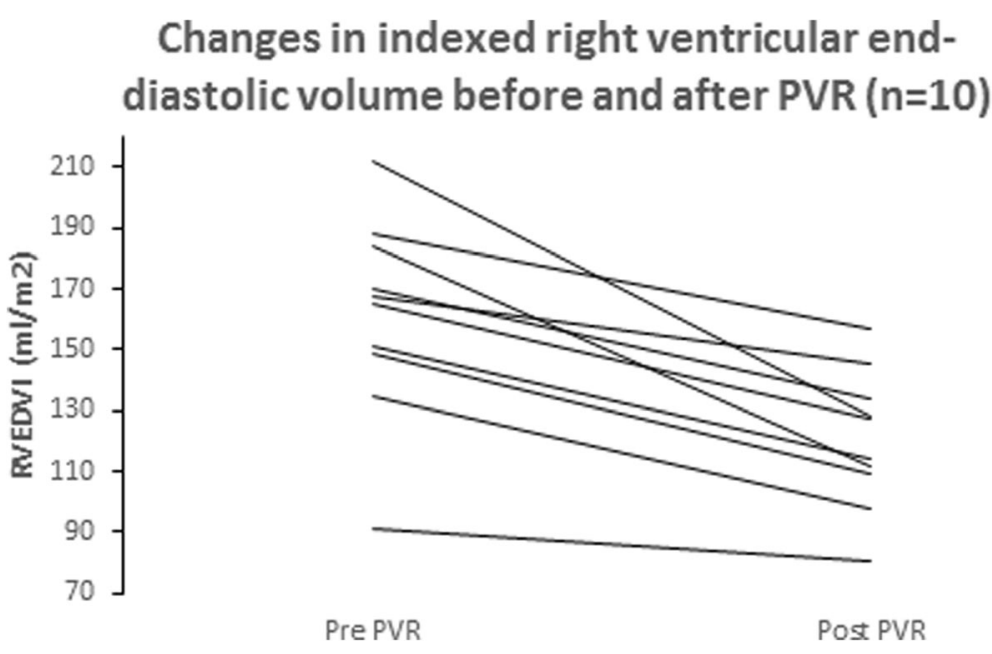

Fig. 1 Changes in indexed right ventricular end-diastolic volume and after PVR 
$97 \mathrm{ml} / \mathrm{m}^{2}$ ) to $90 \pm 15 \mathrm{ml} / \mathrm{m}^{2}$ (range, 61 to $108 \mathrm{ml} / \mathrm{m}^{2}$ ) postoperatively, $p=0.012$.

\section{Discussion}

Data in the present study indicates that even though the preoperative mean RVEDVI exceeded $160 \mathrm{~mL} / \mathrm{m}^{2}$ in the majority of the cases, there was a significant reverse remodelling with a reduction in right ventricular end-diastolic volume 6-12 months postoperatively. However, the RVEDVI did not reach normal values postoperatively in any case but one.

Optimal timing of PVR due to severe PI in TOF is still a subject of debate as beneficial effects of PVR have to be weighed against the risk for repeat PVR. Performing PVR early during follow-up could be associated with an improved RV remodelling [18-21], but it may increase the number of surgical interventions during the patient's lifetime and increasing the accumulated risk of procedure-related complications. However, Vliegan et al. has previously shown that RV volumes were significantly reduced after PVR in adult patients with corrected TOF [22] and attempts have been made to find a cutoff where the RV does not normalize postoperatively in order to facilitate the decision for optimal timing of intervention. Cut-off values for indexed RV end-diastolic volume (RVEDV) between 150 and $170 \mathrm{ml} / \mathrm{m}^{2}$ have been proposed as an indication for PVR in asymptomatic adults with congenital heart disease with previously corrected TOF. Therrian et al. has previously reported that the $\mathrm{RV}$ does not reach normal volumes following surgery if the preoperative RVEDVI exceeds $170 \mathrm{ml} / \mathrm{m}^{2}$ [23]. Similarly, in children a cut-off of $200 \mathrm{ml} / \mathrm{m}^{2}$ has been shown to predispose for an incomplete reverse remodelling [24]. According to the current guidelines $[10,11]$ normalization of RVEDVI becomes more unlikely when the preoperative RV volume exceeds the cut-off of $160 \mathrm{ml} / \mathrm{m}^{2}$. In the current study, the preoperative mean RVEDVI was $161 \pm 33 \mathrm{ml} / \mathrm{m}^{2}$. The majority of the patients did not reach normal RVEDVI $(\leq 99$ $\mathrm{ml} / \mathrm{m}^{2}$ ) 6-12 months postoperatively as assessed by MRI. This incomplete pattern of reverse remodeling could also be shown for patients with RVEDVI lower than the cut-off of $160 \mathrm{ml} / \mathrm{m}^{2}$. However, a significant reverse remodeling was present in all patients despite not reaching normal postoperative RV volumes. In addition, RVSVI decreased after surgery, reaching normalization. Data in the present study showing early RV reverse remodeling are consistent with those of previous studies [18, 25-28]. In a meta-analysis including 48 studies involving 3118 patients, Ferraz Cavalcanti et al. [25] showed similar favorable remodeling of the RV mostly between 1 and 3 years after PVR. No clear cutoff for preoperative RVEDVI that "guarantees" normal postoperative RV size has thus been identified. Furthermore, in a report by van Straten et al. RVEDVI decreased only marginally $\left(2 \mathrm{ml} / \mathrm{m}^{2}\right)$ from 7 to 18 months after PVR [29]. This is supported by, Hallbergsson et al. [21] showing that favorable RV reverse remodeling early after PVR erodes during long-term follow-up, with a gradual return toward dilatation and pre-PVR values of RV size and function up to 10 years postoperatively. This is probably associated with increasing PI and pulmonary stenosis related to deteriorating function of the implanted conduit and, in some patients, volume load from tricuspid regurgitation. Therefore, given that the negative consequences of moderate or even severe RV dilatation are questionable, focusing on preoperative RV function appears to be more appropriate.

In the present study, data indicated a positive change in right-to-left ventricular interaction after surgery. The RVEF did not change significantly, $46 \%$ versus $42 \%$ ( $p=$ 0.337) after PVR. However, the preoperative RVEF does not show the actual ejection fraction as approximately $50 \%$ of the stroke volume is regurgitated to the RV. This implies that the RVEF actually improves postoperatively when there is only negligible remaining PI. Furthermore, an increase in LVEDVI, LVESVI and left ventricular stroke volume could be observed postoperatively. Our findings are supported by Oosterhof et al. showing that RV dysfunction may negatively affect left ventricular (LV) function as RV volume overload due to PI correlated to lower RVEF and LVEF as well as higher BNP levels [30]. In our study, both RVEDVI and RVESVI decreased after surgery while net-flow in the main pulmonary artery increased indicating an enhanced RV output. The fact that LVEDVI, LVESVI and LV stroke volume increased after surgery while LVEF remained unchanged may reflect a more favourable right-to-left ventricular interaction with equal stroke volumes and a trend towards improvement of the LV function.

\section{Clinical implications}

This was a prospective study with a consistent cMRI protocol with the following clinical implications. The improvement in RV size following PVR compared to pre PVR measurements assists clinical decisions regarding timing of valve or conduit replacement. However, no clear cutoff for preoperative RVEDVi that "guarantees" normalization of RV size post PVR could be identified. Moreover, given that previous data [21] show gradual $\mathrm{RV}$ enlargement and a decline in global RV systolic function toward pre-PVR values the importance of subsequent surveillance is highlighted. Follow-up should include quantitative assessment of ventricular size and function, bioprosthetic pulmonary valve function - preferably by cMRI. In addition, our results highlight the importance of improving strategies to maintain pulmonary valve competence over several decades. Specifically, given that the inevitable functional deterioration of all currently available bioprosthetic valves and conduits leads to worsening RV mechanics. 


\section{Limitations}

One limitation of this study is the lack of a control group. The relatively small number of patients results in a loss of statistical power, requiring validation using larger groups of patients. Even though our data have been validated previously in larger studies, these have been retrospective and heterogeneous in contrast to our prospective study.

\section{Conclusion}

PVR leads to a favourable early reverse remodelling with a reduction in RV volumes and improved biventricular function. A significant reverse remodeling was present in all patients despite not reaching normal postoperative RV volumes.

\section{Abbreviations}

AST: Aspartate aminotransferase; CK-MB: Creatine kinase myocardial specific isoform; cMRl: Cardiac magnetic resonance imaging;

ECG: Electrocardiography; LV: Left ventricular; LVEDVI: Mean indexed left ventricular end-diastolic volume; LVESVI: Mean indexed left ventricular endsystolic volume; LVSVI: Mean indexed left ventricular stroke volume; MPA: Mean net flow in the main pulmonary artery; PI: Pulmonary insufficiency; PVR: Pulmonary valve replacement; RV: Right ventricular; RVEDVI: Mean indexed right ventricular end-diastolic volume; RVESVI: Mean indexed right ventricular end-systolic volume; RVSVI: Mean indexed right ventricular stroke volume; SV: Stroke volume; TOF: Tetralogy of Fallot

\section{Acknowledgements}

None

\section{Funding}

No financial support has been received.

\section{Availability of data and materials}

Please contact author for data requests.

\section{Authors' contributions}

All have made an important scientific contribution to this study, are familiar with the primary data and have read the entire manuscript and take responsibility for its content. All authors read and approved the final manuscript.

\section{Ethics approval and consent to participate}

Permission to proceed with this study was granted by the institutional Ethics Review Board, Lund, Sweden and individual consent was obtained from all patients enrolled.

\section{Consent for publication}

All authors are aware of the contents of the manuscript and consent to the use of their name author of the manuscript. All authors certify that, to the best of their knowledge:

This manuscript is not currently under consideration, in press or published elsewhere.

This manuscript is truthful original work without fabrication, fraud or plagiarism.

\section{Competing interests}

The authors declare that they have no competing interests.

\section{Publisher's Note}

Springer Nature remains neutral with regard to jurisdictional claims in published maps and institutional affiliations.

\section{Author details}

'Department of Cardiothoracic Surgery, Clinical sciences, Lund University, Skane University Hospital, SE-221 85 Lund, Sweden. ${ }^{2}$ Department of Clinical Physiology, Clinical sciences, Lund University, Skane University Hospital, Lund, Sweden.

Received: 4 December 2018 Accepted: 1 April 2019

Published online: 15 April 2019

\section{References}

1. Alexiou C, Mahmoud H, Al-Khaddour A, et al. Outcome after repair of tetralogy of Fallot in the first year of life. Ann Thorac Surg. 2001;71:494-500.

2. Vida VL, Berggren $\mathrm{H}$, Brawn WJ, et al. Risk of surgery for congenital heart disease in the adult: a multicentered European study. Ann Thorac Surg. 2007;83:161-8.

3. Nollert G, Fischlein T, Bouterwek $\mathrm{S}$, et al. Long-term survival in patients with repair of tetralogy of Fallot: 36-year follow-up of 490 survivors of the first year after surgical repair. J Am Coll Cardiol. 1997;30:1374-83.

4. Oechslin EN, Harrison DA, Harris L, et al. Reoperation in adults with repair of tetralogy of fallot: indications and outcomes. J Thorac Cardiovasc Surg. 1999:118:245-51.

5. Ross DN, Somerville J. Correction of pulmonary atresia with a homograft aortic valve. Lancet. 1966;2:1446-7.

6. Warner KG, O'Brien PK, Rhodes J, et al. Expanding the indications for pulmonary valve replacement after repair of tetralogy of fallot. Ann Thorac Surg. 2003;76:1066-71.

7. Discigil B, Dearani JA, Puga FJ, et al. Late pulmonary valve replacement after repair of tetralogy of Fallot. J Thorac Cardiovasc Surg. 2001;121:344-51.

8. Gatzoulis MA, Balaji S, Webber SA, et al. Risk factors for arrhythmia and sudden cardiac death late after repair of tetralogy of Fallot: a multicentre study. Lancet. 2000;356:975-81.

9. Jang W, Kim YJ, Choi K, et al. Mid-term results of bioprosthetic pulmonary valve replacement in pulmonary regurgitation after tetralogy of Fallot repair. Eur J Cardiothorac Surg. 2012:42:e1-8.

10. Baumgartner $\mathrm{H}$, Bonhoeffer $\mathrm{P}$, De Groot NM, et al. ESC guidelines for the management of grown-up congenital heart disease. Eur Heart J. 2010;31: 2915-57.

11. Warnes CA, Williams RG, Bashore TM, et al. ACC/AHA 2008 guidelines for the management of adults with congenital heart disease: a report of the American College of Cardiology/American Heart Association task force on practice guidelines. J Am Coll Cardiol. 2008;52:e143-263.

12. Nozohoor S, Johansson S, Gustafsson R. Early surgical experience of right ventricular outflow reconstruction with the RVOT Elan conduit in adults and adolescents with congenital heart disease. Congenit Heart Dis. 2014;9:536-42.

13. Geva T. Is MRI the preferred method for evaluating right ventricular size and function in patients with congenital heart disease?: MRI is the preferred method for evaluating right ventricular size and function in patients with congenital heart disease. Circ Cardiovasc Imaging. 2014;7:190-7.

14. Oosterhof T, Mulder BJ, Vliegen HW, de Roos A. Cardiovascular magnetic resonance in the follow-up of patients with corrected tetralogy of Fallot: a review. Am Heart J. 2006;151:265-72.

15. Pennell DJ, Sechtem UP, Higgins CB, et al. Clinical indications for cardiovascular magnetic resonance (CMR): consensus panel report. J Cardiovasc Magn Reson. 2004;6:727-65.

16. Heiberg E, Sjogren J, Ugander M, et al. Design and validation of segment-freely available software for cardiovascular image analysis. BMC Med Imaging. 2010;10:1.

17. Maceira AM, Prasad SK, Khan M, Pennell DJ. Reference right ventricular systolic and diastolic function normalized to age, gender and body surface area from steady-state free precession cardiovascular magnetic resonance. Eur Heart J. 2006;27:2879-88.

18. Frigiola A, Tsang $\vee$, Bull C, et al. Biventricular response after pulmonary valve replacement for right ventricular outflow tract dysfunction: is age a predictor of outcome? Circulation. 2008;118:S182-90.

19. Geva T. Repaired tetralogy of Fallot: the roles of cardiovascular magnetic resonance in evaluating pathophysiology and for pulmonary valve replacement decision support. J Cardiovasc Magn Reson. 2011;13:9.

20. Geva T. Indications for pulmonary valve replacement in repaired tetralogy of fallot: the quest continues. Circulation. 2013;128:1855-7.

21. Hallbergson A, Gauvreau K, Powell AJ, Geva T. Right ventricular remodeling after pulmonary valve replacement: early gains, late losses. Ann Thorac Surg. 99:660-6. 
22. Vliegen HW, van Straten A, de Roos A, et al. Magnetic resonance imaging to assess the hemodynamic effects of pulmonary valve replacement in adults late after repair of tetralogy of fallot. Circulation. 2002;106:1703-7.

23. Therrien J, Provost $\mathrm{Y}$, Merchant $\mathrm{N}$, et al. Optimal timing for pulmonary valve replacement in adults after tetralogy of Fallot repair. Am J Cardiol. 2005;95: 779-82.

24. Buechel ER, Dave HH, Kellenberger $\mathrm{CJ}$, et al. Remodelling of the right ventricle after early pulmonary valve replacement in children with repaired tetralogy of Fallot: assessment by cardiovascular magnetic resonance. Eur Heart J. 2005;26:2721-7.

25. Ferraz Cavalcanti PE, Sa MP, Santos CA, et al. Pulmonary valve replacement after operative repair of tetralogy of Fallot: meta-analysis and metaregression of 3,118 patients from 48 studies. J Am Coll Cardiol. 2013;62: 2227-43.

26. Geva TK, Gauvreau AJP, et al. Randomized trial of pulmonary valve replacement with and without right ventricular remodeling surgery. Circulation. 2010;122:5201-8.

27. Lee C, Kim YM, Lee CH, et al. Outcomes of pulmonary valve replacement in 170 patients with chronic pulmonary regurgitation after relief of right ventricular outflow tract obstruction: implications for optimal timing of pulmonary valve replacement. J Am Coll Cardiol. 2012;60:1005-14.

28. Therrien J, Siu SC, McLaughlin PR, et al. Pulmonary valve replacement in adults late after repair of tetralogy of fallot: are we operating too late? I Am Coll Cardiol. 2000;36:1670-5.

29. van Straten A, Vliegen HW, Hazekamp MG, et al. Right ventricular function after pulmonary valve replacement in patients with tetralogy of Fallot. Radiology. 2004;233:824-9.

30. Oosterhof T, Tulevski II, Vliegen HW, Spijkerboer AM, Mulder BJ. Effects of volume and/or pressure overload secondary to congenital heart disease (tetralogy of fallot or pulmonary stenosis) on right ventricular function using cardiovascular magnetic resonance and B-type natriuretic peptide levels. Am J Cardiol. 2006;97:1051-5.

Ready to submit your research? Choose BMC and benefit from:

- fast, convenient online submission

- thorough peer review by experienced researchers in your field

- rapid publication on acceptance

- support for research data, including large and complex data types

- gold Open Access which fosters wider collaboration and increased citations

- maximum visibility for your research: over $100 \mathrm{M}$ website views per year

At $\mathrm{BMC}$, research is always in progress.

Learn more biomedcentral.com/submissions 